R. Italianística, ano IV, n. 4, p.53-60, 1996

\title{
ONDE O VERMELHO E O VERDE SATO CORES MUITO ESTRANHAS
}

Gabriela Kvacek Betella*

Resumo: Proposta de leitura da obra de Carlo Levi, Cristo si è fermato a Eboli.

Palavras-chave: literatura italiana do século $\mathrm{XX}$, neo-realismo, romance, exílio.

"Anche allora si seguivano i tre colori, che qui sembrano strani, $i$ colori araldici di un'altra Italia, incomprensibile, volontaria e violenta, quel rosso allegremente sfacciato e quel verde cosi assurdo quaggiù, dove anche gli alberi sono grigi, e l'erba non cresce sulle argille. (...) Che cosa hanno a che fare con quelli i contadini? Il loro colore è uno solo, quello stesso dei loro occhi tristi e dei loro vestiti, e non è un colore, ma è l'oscurità della terra e della morte."

Carlo Levi. Cristo si è fermato a Eboli.

\section{Tempo de narrar}

Normalmente, a fortuna crítica do neo-realismo literário italiano situa Cristo si è fermato a Eboli como um meio-termo entre narrativa e ensaio. $\mathrm{O}$ romance mais conhecido de Carlo Levi não se enquadraria nos gêneros literários tradicionais por ser um pouco diário, ensaio histórico e sociológico, testemunho, reflexão e descrição de cenas de vida camponesa. De qualquer forma, é uma obra capaz de aliar os recursos de uma narrativa de memória à vivacidade quase de uma crônica de viagem. Aliar uma precisão de descrições à expressão da proximi-

* Graduada em Língua e Literatura Italiana, mestranda em Teoria Literária e Literatura Comparada na FFLCH-USP. 
BETELLA, Gabriela Kvacek. Onde o vermelho e o verde säo cores muito estranhas.

dade entre fatos narrados e narrador é uma peripécia um tanto rara no romance contemporâneo, mas é, a meu ver, o grande trunfo da narrativa neo-realista.

Após a Segunda Guerra, o neo-realismo italiano (que já fora delineado nos anos 30) passou a ser uma das mais autênticas formas de conhecimento de uma realidade desordenada. A literatura e o cinema não só registraram os anos da guerra e da luta de libertação ou resistência, como também puderam representar examinando, tomando consciência da relação profunda entre arte e sociedade. O escritor e o cineasta partiam de sua atualidade - que incluía pontos de vista, exigências, denúncias e a moral de um movimento revolucionário real - e passavam a refletir sobre ela. A forma "acabada" da reflexão era a própria obra. Aproveitando uma expressão de Walter Benjamin considerando a produção literária, na qual fica claro que o artista (no caso, o escritor) que não ensina outros artistas não ensina ninguém $1_{-}$, posso afirmar que o neo-realismo ultrapassa a classificação de literatura "empenhada" e a postura da arte sem autocrítica, sem agressividade e sem polêmicas.

Costuma-se dizer que o neo-realismo literário italiano adquiriu uma linguagem totalmente nova, que pôde incorporar a urgência da expressão dos valores humanos e sociais dando-lhe voz gritante e status de obra literária. De fato, a narrativa neo-realista assume pontos de vista capazes de documentar; em alguns casos, porém, a riqueza de nuances é tamanha que a imparcialidade exigida para o narrador de um documentário é relativa - talvez por isso podemos oferecer a obras como Cristo si è fermato a Eboli o estatuto de romance. A narrativa neorealista é testemunho mesmo sendo ficcional. A "nova linguagem" trabalha velhos ensinamentos da arte de narrar histórias, diretamente ligados ao envolvimento do ouvinte/leitor. Coisas muito comuns à crônica, que pode servir, em muitos casos do neo-realismo, como um paradigma e até mesmo como uma espécie de "gênero de fundo" em alguns romances.

Há uma distância entre a composição e os acontecimentos: Cristo si è fermato a Eboli foi escrito em Florença entre 1943-44, os últimos anos da guerra, evocando o período de 1935-36 e os cenários da Lucânia, do exílio de Levi. Nessa revisitação, a narrativa move esforços para expressar um material que jamais poderia ser trazido no bolso, porque faz parte da experiência. Trabalhando com a matéria da experiência o autor está imune, num certo sentido, dos horrores da guerra, porque essa matéria não pode ser retirada pela imposição nem saqueada.

O estilo de narrar transcende o mero relato de lembranças ou de recordações e é atrativo, pois reelabora as imagens da memória durante o próprio ato da narração, daí a vivacidade impressionante. A dramaticidade do discurso de Carlo Levi é sutil, mascarada pelo caráter ensaístico que parece se colocar no tom certo. Não

1 BENJAMIN, W. "O autor como produtor". In: Obras escolhidas: magia e técnica, arte e política. Sāo Paulo: Brasiliense, 1993, p. 132. 
há marcas de romanesco; contudo, o relato exerce o poder de seduçāo do romance. Alguns motivos dessa sedução são o que pretendo investigar.

Boa parte da atração exercida pelo romance de Carlo Levi no leitor está associada à matéria de que trata: a questão meridional e a microhistória traçada pelo cotidiano de uma região da Basilicata. A meu ver, o estilo, a vivacidade da perspectiva da descoberta enriquece muito a composição: à medida que os fatos são narrados, sente-se que o narrador está surpreso, por vezes assustado, tanto quanto o leitor que também estranha aquela outra Itália tão longe e tāo perto do progresso civil, tão destacada e tāo encravada no país que traça a sua História e sua glória com as guerras. Tal perspectiva é sabiamente utilizada, uma vez que o leitor se aproxima dos fatos sem deixar de estar consciente da mediação.

\section{Esperando uma festa de Babette}

Curiosamente, o atestado de veracidade das pessoas, do tempo e do espaço de Cristo si è fermato a Eboli passa pela sensibilidade do olhar do pintor e pelas preocupaçōes do homem político Carlo Levi. Esse lembrete é válido para as leituras que partem da composiçāo de um universo, digamos, "parado no tempo" Ao observar a inserção das personagens numa paisagem tão condizente com a sua existência e com a sua falta de perspectivas, é plausível uma interpretaçāo que estabeleça relações de conformidade ou de condicionamento. E um leitor de romances poderá transferir para a sua leitura do microcosmo de Gagliano algumas reaçōes provocadas, por exemplo, pela ansiedade da espera pelo desfecho, pela reviravolta na vida supersticiosa e miserável, com base na construçāo das imagens que o texto vai permitindo - até aqui, há qualquer coisa da atmosfera sugerida pelo notável $A$ Festa de Babette.

No entanto, é o próprio andamento do texto que bloqueia qualquer interpretação relacionada a acontecimentos decisivos (como a chegada de um forasteiro e sua interferência nos destinos). Nāo há entrecho romanesco, assim como não há heróis em Cristo si è fermato a Eboli. As descrições investigam e os acontecimentos narrados compõem um universo de diferenças sociais profundas. $\mathrm{O}$ texto faz a microhistoriografia sem deixar de envolver as noções de poder e de consciência humana, histórica, política, social. E, ainda que seja capaz de atirar as personagens numa espécie de "inércia da ausência de esperança", a obra desperta um sentimento de vida. Quando tem a certeza de que a festa nāo virá, o leitor tira o proveito da obra.

Há muitas passagens notáveis quanto ao seu alcance analítico. No início do relato, por exemplo, o narrador chega a traçar o perfil topográfico e o perfil comportamental de Gagliano, utilizando-se da comparação entre Gagliano e 
BETELLA, Gabriela Kvacek. Onde o vermelho e o verde säo cores muito estranhas.

Grassano num primeiro momento e da exploração dos valores (nacionais, principalmente) nas pessoas. Assim, Gagliano, a segunda cidade do exílio, é incansavelmente descrita e logo apresentada como

"un piccolissimo paese, e lontano dalle strade e dagli uomini: le passioni vi sono perciò più elementari, più semplici, ma non meno intese che altrove; e non sarà difficile, immaginavo, averne presto la chiave"2.

Em Grassano, o narrador já havia passado um ano do exílio, e é através da comparação que se estabelecem as dúvidas em relação à nova estada:

"Grassano è invece piuttosto grande, su una via di passaggio, non lontano dal capoluogo della provincia: non c'è, come qui [Gagliano], il contatto continuo di tutti con tutti; le passioni possono perciò essere più nascoste, prendere una forma più mediata, vestirsi di aspetti più complessi. I segreti di Grassano mi erano stati rivelati fin dai primi giorni del mio arrivo da uno dei loro più appassionati protagonisti. Quelli di Gagliano, come li conoscerò? A Gagliano devo passare tre anni, un tempo infinito. Il mondo è chiuso: gli odi e le guerre dei signori sono il solo avvenimento quotidiano: e ho già visto sui loro volti come esse siano radicate e violente, miserabili ma intense come quelle di una tragedia greca. Bisognerà pure che, come un eroe di Stendhal, io faccia i miei piani, e non commetta errori. A Grassano, il mio informatore era stato il capo della Milizia, il tenente Decunto. Chi lo sarà quaggiù?"' (20)

A partir daqui, retomando as questōes que envolviam os ódios seculares (que nem mesmo o fascismo pôde alterar), em Grassano, fica claro que o forasteiro tem o olhar privilegiado, mas ele também é o prisma que decompõe situações aparentemente explicáveis pelos antagonismos antigos; é muito pior soterrar esses antagonismos com um fascismo no qual "estão todos", mas isso não podia dizer nada: antes de tudo, era uma terra de galantuomini e brigant ${ }^{3}$, raízes de todos os ódios. O resultado que o narrador observa, através da ótica do tenente Decunto, é uma guerra contínua que não toma forma de uma luta política real, porque se

2 LEVI, C. Cristo si è fermato a Eboli. Torino: Einaudi, 1975, p. 20. As referências seguintes trazem, entre parêntesis, a página desta ediçăo.

3 O brigantaggio ou guerra dos briganti se desenvolve depois da proclamaçáo da unidade italiana; foi ao mesmo tempo guerrilha de grupos fiéis aos Bourbons contra a unificaçāo e fenômeno social de revolta contra abusos, quase símbolo de justiça popular. 
faz entre senhores do mesmo grupo e em todos os lugares da Lucânia. Como os jovens burgueses aventuram-se a sair para Nápoles, Roma ou para a América, uma "classe burguesa degenerada" precisa

"per vivere (i piccoli poderi non rendono quasi nulla), poter dominare $i$ contadini, e assicurarsi, in paese, $i$ posti remunerati di maestro, di farmacista, di prete, di maresciallo dei carabinieri, e cosi via. Ė dunque questione di vita o di morte avere personalmente in mano il potere".(24)

O "espaço vital" necessário para essa classe degenerada só poderia ser a conquista da África, segundo o tenente, para o qual também não importava a vitória ou a derrota na empresa; bastava enterrar a lembrança de Grassano. $\mathrm{O}$ narrador vai esboçar um instigante contraponto para essa iniciativa, ainda que alegoricamente, descrevendo uma peculiaridade de Gagliano:

"Qui, dove il tempo non scorre, è ben naturale che le ossa recenti, e meno recenti e antichissime, rimangano, ugualmente presenti, dinanzi al piede del passeggero". (62)

Mas quando o narrador concentra sua capacidade na expressão mais envolvente da realidade é que observamos a maior e mais fina capacidade analítica. São alguns episódios tocantes como o veto do exercício da medicina ao exilado. Para dar a dimensão da insensatez das "ordens superiores" e do incômodo causado pelo médico que iniciava uma luta antimalária, surge um homem doente em Pantano, e o irmāo a pedir a ajuda do doutor. Horas depois, a insistência no pedido, e a descrição da agonia até a permissão para "don" Carlo atender o doente, cuja peritonite não permitia mais nada além da morfina e da paciência em esperá-lo morrer.

O jovem de Gaglianello com a lesão na artéria interdigital (o narrador arrasa nos termos médicos e cirúrgicos) e a prepotência do doutor Milillo que é posta em choque com a humildade de "don" Carlo - também sustentam uma espécie de lirismo cortante, sem uma busca de explicação definida. Resgatando experiências tão duras, a narrativa trabalha a matéria-prima que poderia ser escondida, evitada, mas que constitui a via pela qual se restabelece a dimensão das coisas. 
BETELLA, Gabriela Kvacek. Onde o vermelho e o verde são cores muito estranhas.

\section{No calor da hora}

Finalmente, vale insistir na presença do espírito crítico capaz de operar uma mudança de tom nos últimos momentos do relato, deixando muito claras as intençōes do "ensaio" Cristo si è fermato a Eboli e, principalmente, explicitando a retomada dos fatos descritos sob uma pressão talvez mais ameaçadora do que fora o exílio. Quando o narrador questiona as reflexōes sobre o problema meridional, seu relato ganha passagens com ares teóricos, muito esclarecedoras, que arrematam as considerações do observador que descrevia a Lucânia. Há, sobretudo, uma certeza de que as reflexões sobre o mezzogiorno, sobre o problema meridional, esquecidas durante o fascismo, não poderiam ser retomadas como uma espécie de mediadoras das questões de partido, de classe ou de raça. Assim, relacionar o problema meridional italiano a problemas econômicos, a uma herança histórica, à opressão capitalista, a uma inferioridade de raça é o primeiro passo para pedir providências ao Estado. Contudo, diz Levi:

"lo Stato, come essi lo intendevano, era invece l'ostacolo fondamentale a che si facesse qualunque cosa. Non può essere lo Stato (...) a risolvere la questione meridionale, per la ragione che quello che noi chiamamo problema meridionale non è altro che il problema dello Stato" (220)

Há dois lados nas constatações teóricas do texto: o primeiro, que diz respeito ao fazer literário, mostra que as "fórmulas e esquemas" dos teóricos e a própria linguagem pela qual se expressavam não podiam exprimir a realidade do sul do país, porque não constituíam meios de penetrar aquele tipo de vida; a segunda face do "ensaio" evidencia a distância entre a unidade, o poder centralizador de um Estado que se pretende fascista, liberal, socialista ou de qualquer outra forma pequeno-burguesa e o total "antistatalismo dei contadini". Cristo si è fermato a Eboli aponta para soluçōes nos dois lados.

Indiscutivelmente, o livro foge das formas tradicionais do romance; a narrativa lida com um material de origem especificada, inclusive no mapa da Itália, e precisa elevá-lo à condição de obra de arte. O caminho encontrado dispensa brincadeiras com o ponto de vista, típicas dos romances inovadores de tempos de crise. O narrador de Cristo si è fermato a Eboli apresenta-se como homem culto, filtra sua expressão com sua sabedoria, mas o seu tratamento do discurso não dispensa os dados da experiência muito "miúda" dos contadini da Lucânia. Dessa forma, a sensação de verdade real almejada pelo discurso que se compõe num tempo de crise - em plena Segunda Guerra - é reforçada pelos modos de ação e expressão peculiares de uma região problemática "desde sempre", sem o 
provincianismo da imitação de estilos literários e sem o "aristocratismo compensatório" de narrativa culta que trata problemas impossíveis de evitar.

A guerra torna-se estímulo para uma criação caracterizada pelo "regionalismo" sutil, sem vestígios de exotismos. Um impressionante fio de memória sem emendas é a base da obra que levava em conta também "a contemporaneidade infinita e poética dos tempos e dos destinos", conforme explica o próprio autor em $19633^{4}$. Na época da composição, o livro era uma defesa ativa, pois cada momento poderia ser o último; por essa razão, não havia lugar para ornamentos, para experimentos, enfim, para literatura - só havia lugar para a verdade real.

Quando a narrativa se abre, há uma referência clara ao tempo da composição. Intencionalmente ou não, o narrador explica sinteticamente o procedimento que guia o desenvolvimento do texto, não obstante estar, de fato, encerrando um processo:

"Sono passati molti anni, pieni di guerra, e di quello che si usa chiamare la Storia. Spinto qua e là alla ventura, non ho potuto finora mantenere la promessa fatta, lasciandoli, ai miei contadini, di tornare fra loro, e non so davvero se e quando potrò mai mantenerla. Ma, chiuso in una stanza, e in un modo chiuso, mi è grato riandare con la memoria a quell'altro mondo, serrato nel dolore e negli usi, negato alla Storia e allo Stato, eternamente paziente; a quella mia terra senza conforto e dolcezza, dove il contadino vive, nella miseria e nella lontananza, la sua immobile civiltà, su un suolo arido, nella presenza della morte". (3)

Se, por um lado, a estrutura da obra é definida com base na cuidadosa exteriorização da memória, tornando-se narrativa pessoal, por outro ela se constitui num tempo de expressão certeira, imediata e necessária de uma verdade "sempre presente".

O breve episódio com o Arcebispo pode servir como arremate na evidenciação das diferenças ou do "abismo" entre duas Itálias hostis, cujos resultados estão "na guerra atual (Abissínia) e nas que virão". O procedimento do narrador internaliza essas diferenças como fatores estéticos, enfrentando, de fato, os problemas, e por escrito - principalmente quando o texto dá suas conclusões teóricas, sem perder aquele fio de romance de memória:

"Il vero nemico, quello che impedisce ogni libertà e ogni possibilità di esistenza civile ai contadini, è la piccola borghesia dei paesi. È

$4 \mathrm{Na}$ apresentação do romance ao editor Giulio Einaudi. 
BETELLA, Gabriela Kvacek. Onde o vermelho e o verde são cores muito estranhas.

una classe degenerata, fisicamente e moralmente: incapace di adempiere la sua funzione, e che solo vive di piccole rapine e della tradizione imbastardita di un diritto feudale. Finché questa classe non sarà soppressa e sostituita non si potrà pensare di risolvere il problema meridionale. (...)"

"Così avevo detto ai miei amici, e andavo ora rimeditando mente il treno, nella notte, entrava nelle terre di Lucania. Erano i primi accenni di quelle idee che dovevo poi sviluppare negli anni seguenti, attraverso le esperienze dell'esilio e della guerra. $E$ in quest $i$ pensieri mi addormentai". (222-223)

Tratando de formular uma experiência individual, Cristo si è fermato a Eboli toca os problemas nas escalas pública e individual, sem jamais se interessar pela vida privada exclusivamente no âmbito memorialista. Finalizando, estamos diante de uma narrativa que expõe, o tempo todo, como as cores de uma bandeira podem e, ao mesmo tempo, não podem significar alguma coisa, devido às diferenças profundas na realidade de um país. Mais que isso, a narrativa de Carlo Levi utiliza (parafraseando Jorge Luis Borges) os tempos de declínio ou de crise para pensar os próprios limites - de nação, de homem, de narração -, pois o ato se torna promessa de que nenhuma calamidade nem ditadura poderá nos empobrecer.

Abstract: The article proposes a way of reading of the book Cristo si è fermato a Eboli by Carlo Levi.

Keywords: Italian literature of XX century, neorealism, novel, exile. 